\section{B A Institute of \\ YK Business Administration \\ 光 \\ Karachi \\ Leadership and Ideas for Tomorrow}

\section{Business Review}

\section{Volume 10 Issue 2} July-December 2015

7-1-2015

\title{
Does ESG investment enhance investment returns
}

CA. Hemlata Chelawat

MLS University, Udaipur, India

I.V. Trivedi

MLS University, Udaipur, India

Follow this and additional works at: https://ir.iba.edu.pk/businessreview

Part of the Environmental Studies Commons, Finance Commons, Growth and Development Commons, and the Public Economics Commons

(c) (i)

This work is licensed under a Creative Commons Attribution 4.0 International License.

\section{Recommended Citation}

Chelawat, C. H., \& Trivedi, I. (2015). Does ESG investment enhance investment returns. Business Review, 10(2), 100-115. Retrieved from https://doi.org/10.54784/1990-6587.1356

This article is brought to you by iRepository for open access under the Creative Commons Attribution 4.0 License and is available at https://ir.iba.edu.pk/businessreview/vol10/iss2/7. For more information, please contact irepository@iba.edu.pk. 


\title{
ARTICLE
}

\section{DOES ESG INVESTMENT ENHANCE INVESTMENT RETURNS}

CA.Hemlata Chelawat, MLS University, Udaipur, India.

\author{
I.V. Trivedi, MLS University, Udaipur, India.
}

\section{Abstract}

Over the past decade, Environmental, Social and Governance Investment or ESG Investment has become a mainstream investment approach in the investment community around the world, especially in the US and Europe. There is increasing evidence from academic and practitioner research around the world that better ESG performance by companies leads to reduction in risks, improvement in financial performance, higher stock market valuations and hence, enhanced returns for investors investing in stocks of such companies. Hence, incorporating ESG factors can lead to better informed and improved investment decisions. This has led to development of ESG indices and funds, to enable investors to identify high ESG performing companies for investment purposes. Absence of convincing research on the performance of ESG investment has been one of the major factors responsible for the slow adoption of this valuable investment approach in developing economies like India.

This study aims at empirically investigating the performance of ESG investment in an emerging economy - India. For the purpose, it analyses the risk-return performance of ESG India Index as compared to the conventional benchmark index, using the Capital Asset Pricing Model and the Brown-Forsythe Levene's Test. The findings distinctively reveal that even in the short time since inception, ESG India Index outperforms the conventional index and hence, ESG investing enhances investment returns, without any significant difference in risk. Thus, it provides valuable guidance to investors that they can invest in highly rated ESG stocks without paying a penalty in terms of investment returns. This paper makes valuable contribution to empirical literature on ESG investment in developing economies, specifically India. It has important implications for the regulatory agencies, governments and other international organisational initiatives which are trying to popularise ESG investment, particularly in emerging economies.

Keywords: Investment decisions, Risk-Return performance, Volatility, Analysis, ESG Investment.

JEL Categories: G11, G17, G39.

\section{Introduction and Significance of the study}

Over the past decade, screening of investments for environmental, social and governance (ESG) factors has become a mainstream investment approach in the investment community. ESG investment has recorded an impressive growth in recent times, accounting for about 17 percent of the assets under management in Europe, according to Eurosif estimates; and about $\$ 3.74$ trillion or 11 percent of the assets under management in US, according to GSIA reports (Eurosif, 2009; Global Sustainable Investment Alliance, 2013). In India, about Rs. 1 trillion ( $\$ 18$ billion) of capital is being invested using environmental and social screening measures annually, according to an estimate by cKinetics (cKinetics, 2013). As public awareness of the environmental and social impacts of corporate activity has grown, 
there is a growing awareness that business valuations are often based on incomplete information - they do not factor information on intangibles like ESG risks and opportunities. There is increasing evidence in academic literature that ESG factors can play an important role in creating or eroding shareholder value, as corporate financial returns cannot be delineated from environmental and social impact. Hence, incorporating ESG factors can lead to better informed and improved investment decisions. This realization led to creation of new products like ESG indices and funds that offer investors the opportunity to invest in stocks of companies with high ESG ratings.

But, many are still unconvinced about this business case rationale for ESG investments. Whether or not 'ESG screened indices or funds' impose a penalty in terms of investment returns, has been the subject of much debate. Many analysts believe that screening stocks for ESG considerations reduces the potential universe of investable stocks, thus reducing diversification and increasing risk. Infact, there is no unanimity among both academicians and practitioners about the relationship between corporate ESG ratings and stock market valuations (Jemel, 2008; Orlitzky et al, 2003). The most important question asked by investors is whether ESG investment enhances investment performance or it entails a trade-off in terms of financial risk and return. To provide an answer to this question, many studies across the world have examined the performance of ESG funds, portfolios and indices in comparison to their conventional benchmark. But, this valued investment philosophy is almost un-researched in emerging economies, including India. Absence of convincing research on the performance of ESG funds and indices, as compared to conventional benchmarks has been identified as one of the major factors impeding the adoption and growth of ESG investment in India. A better understanding of the relationship between ESG investment and investment returns may prove to be very significant for encouraging the adoption and growth of ESG investment in emerging economies, including India.

This paper examines the performance of ESG investment in India using ESG index data. Specifically, it empirically investigates the risk - return performance of India's sole1 ESG screened index - S\&P ESG India Index2 and compares it with the unscreened benchmark - Nifty 50 and provides investors with guidance on whether investing in highly rated ESG stocks would impose penalty in terms of investment returns or not.

The remainder of the paper is organized as follows: The next section discusses the relevant literature on the subject. The third section states the objectives of the study. The fourth section describes the research methodology adopted for the study, including the data and variables used and the techniques and tests employed for the study. The fifth section presents the data analysis and results. The sixth section presents the conclusions of the study.

\section{Literature Review}

Many studies have examined the relationship between ESG ratings and market valuations or investment returns. This has been done by assessing performance of highly rated ESG stocks, ESG screened indices and funds as compared to conventional indices or benchmarks. These studies were undertaken in different nations of the world, at different time periods and used different methodologies.

\footnotetext{
${ }^{1}$ Another ESG index - Thomson Reuters ESG Index has recently been launched in India but volumes have yet to pick up \& data has to be available for a longer period for any meaningful analysis.

${ }^{2}$ The S\&P ESG India Index has now been renamed as MSCI ESG India Index due to change in index maintaining services.
} 
Dowell, Hart and Yeung (2000) revealed that companies with highest environmental ratings have higher market valuations and stock prices. Guenster, Derwall, Bauer and Koedijk (2005) proved that firms with high environmental ratings had higher stock prices and returns.Balasubramanian, Black, and Khanna (2009), researched the relationship between governance measures \& firms' financial performance in India, using an own built governance index and found statistically significant positive relationship.

Havemann \& Webster (1999) constructed five different ethical indices, compared their performance with the FTSE All Share Index, and revealed that the performance of ethical indices was similar to FTSE All Share Index, over the entire period of study.Abramson \& Chung (2000) found that SRI index produces superior returns as compared to benchmarks.Statman (2005) compared the performance of four socially responsible indices with conventional stock index and found that the four SRI indices, examined in the study, showed better performance than conventional S \& P 500 Index.Krosinsky \& Robins (2008) proved that the performance of ethical investment is superior to, or at least at par with other market indices. Similar inference of superior performance of ESG indices, as compared to conventional indices, was reported by Norup \& Gottlieb (2011), in their study of the Danish Market.

Bauer, Otten, \& Rad (2004) analysed risk - adjusted returns of ethical mutual funds vs. conventional mutual funds in Australia and found no significant difference in their performance.Bello (2005) concluded that SRI screening did not result in difference in portfolio diversification and risk - adjusted performance of SRI funds as compared to conventional funds.Kreander, Gray, Power, \& Sinclair (2005) used matched pair analysis to compare the performance of 30 European ethical funds with their non-ethical counterparts, and concluded that there is no significant difference between the performances of ethical and non- ethical funds. Bauer, Derwall, \& Otten (2007) analysed the performance and risk of Canadian ethical mutual funds vs. conventional funds and inferred that Canadian investors can invest in ethical mutual funds without having a reduction in their investment returns. Renneboog, Horst, \& Zhang (2007) investigated the performance of 455 ethical and SRI equity funds from all around the world and inferred that they underperform benchmarks by about five percent per annum because SRI fund managers are not able to time the market.

Terayama (2010) found that corporate ESG initiatives reduce risks and increase profitability; which leads to increase in demand of shares of such companies and hence, their share prices, thus benefitting investors who invest in companies based on their ESG performance.

Banerjee \& Orzano (2010) inferred that ESG India Index consistently outperformed the Nifty in terms of price. Adajania (2010) analysed the returns of Fortis Sustainable Development Fund (FSDF), India's first and only SRI mutual fund at that time, and revealed underperformance as compared to conventional funds. He reasoned that this was because ethical investing has yet to catch up in India. Research attempting to analyse the risk - return performance of ESG screened indices or funds is virtually absent in India.

\section{Objectives of the study}

The purpose of this study is to empirically investigate whether ESG investment improves overall investment return i.e. whether an investor using ESG criteria for investment derives enhanced investment returns. The study provides a comparison of the performance of India's first ESG Index - the S\&P ESG India Index against the benchmark CNX Nifty 50 Index to assess the impact of ESG investing on investment performance.Using daily index data from the S\&P ESG India Index and S\&P CNX Nifty Index in India, the paper examines (i) whether the return of the S\&P ESG India Index is different from the benchmark Nifty and, whether the difference is significant statistically and (ii) whether there is significant difference in the volatility (risk) of the two indices under study. 


\section{Research Methodology}

\section{Approach}

One method of assessing financial performance of ESG investments is analysis of financial performance of ESG funds and indices. However, the analysis of performance of ESG funds does not merely reflect the returns of the underlying securities; but also the fund manager's decisions regarding sector and asset selection, the market timing ability of the fund manager, and the differences in management fees and transaction costs due to difference in investment objectives and policies. Due to the impact of these proven influential factors, it becomes extremely difficult to establish the difference that application of ESG criteria has on fund performance. The performance analysis of ESG indices provides a better picture in comparison, as it avoids these biases and tests the joint performance of the underlying stocks that are selected using ESG criteria. Hence, it shows more clearly whether ESG investments perform better or worse as compared to traditional unscreened investments. Therefore, the performance of ESG screened indices is examined which reflects the performance of actively managed ESG funds and index funds also. India has only one ESG index as compared to the plethora of ESG indices available abroad. Therefore, to assess whether ESG factors affect investment performance, the performance characteristics of India's sole ESG index- S\&P ESG India Index are analysed and compared with the unrestricted benchmark CNX Nifty 50 . The performance characteristics compared are price performance, returns and risks.

\section{Data}

For the analysis of the performance of Indian ESG index, historical daily index price data of S\&P ESG India Index and CNX Nifty was used. The aforementioned data was obtained from NSE website www.nseindia.com. Data was obtained for the period January 30, 2008 (the date of launch of the S\&P ESG index) to January 31, 2013, after which no data was available for the ESG index, for the next year, due to change in index maintaining services. The daily index data was available for all trading days except for 7 days over the sample period, when the data for the ESG index was not available. Corresponding data for Nifty was also removed from the dataset for the study, thus amounting to a data of 1255 trading days. Closing value of the indices has been used for the purpose of this study, which was obtained from the NSE website. It has been assumed that all trading is done at closing value.

\section{Variables}

The sub - parameters or variables used for the analysis are as follows:

$>$ Price: The historical price performance of the two indices over the five year period, beginning from $31^{\text {st }}$ January 2008 (the date of inception of the S\&P ESG India

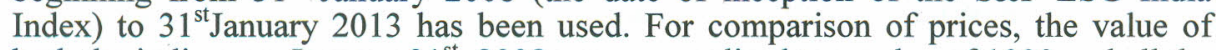
both the indices on January $31^{\text {st }}, 2008$ were normalised to a value of 1000 and all the subsequent values of the two indices were computed taking the base index value as 1000 .

$>$ Returns: Monthly returns have been computed using the formula:

$\mathrm{R}_{\mathrm{t}}=\left(\frac{P t}{P t-1}-1\right) * 100$

where, $R_{t}$ is monthly index return for month $t$,

$\mathrm{P}_{\mathrm{t}}=$ the closing value on last day of month $t, \&$

$\mathrm{P}_{\mathrm{t}-1}=$ the closing value on last day of month $\mathrm{t}-1$.

Excess Returns: The monthly excess returns have been computed by deducting the risk - free interest rate from the returns of both the indices.In January 2012, the 
Indian government had a local currency sovereign rating of Baa3. The typical default spread (over a default free rate) for Baa3 rated country bonds in early 2012 was $2 \%$. This rate has been taken as the average risk-free rate for the period (Damodaran, n.d.).

Risk: To assess the risk of the ESG index as against its benchmark, volatility of returns is studied. There are many ways of measuring volatility but the most common statistical measure of volatility or risk is standard deviation of returns. In finance, standard deviation is applied to the rate of return of an investment to measure its volatility (Investopedia, n.d.). It shows the deviation of the index or fund return in each period from its mean return. Hence, volatility has been calculated as the standard deviation of monthly index returns.

Symbolically, Standard Deviation $\left(\sigma_{\mathrm{r}}\right)=\sqrt{\frac{1}{n-1} \sum_{i=1}^{n}\left(r_{i}-\bar{r}\right)^{2}}$

where, $n$ is the number of monthly returns,

$r_{i}$ is the investment return for the period $i$, and

$\bar{r}$ is the mean return for the entire period.

\section{Research techniques and tests used}

The data was screened for normality and stationarity and then, subject to preliminary analysis to have an initial idea about the performance of the ESG India Index as compared to its benchmark. The Capital Asset Pricing Model and Brown Forsythe Levene's. Test is then employed for further analysis. The main models and tests used for the analysis of the data are as detailed under:

$>$ Jarque-Bera Test and Doornik-Hansen test: The Jarque-Bera test is used to test for normality of the data before using parametric statistical tests which require normally distributed data. The Jarque-Bera (J-B) test is a normality test based on sample skewness and sample kurtosis. The J-B test statistic can be calculated as:

$\mathrm{J}-\mathrm{B}=N\left[\frac{S_{S}^{2}}{6}+\frac{\left(K_{S}-3\right)^{2}}{24}\right]$; where $\mathrm{n}$ is the sample size,

$\mathrm{S}_{\mathrm{s}}$ is the sample skewness coefficient, and

$\mathrm{K}_{\mathrm{S}}$ is the excess kurtosis of the sample over the value of 3 .

Most studies use the Shapiro-Wilk's test for normality but this test as originally proposed by Shapiro and Wilk (1965) was meant for sample sizes between 3 and 50 . The J-B test is valid for 'large samples', as opposed to Shapiro-Wilks for the small samples, and application of J-B to small samples may result in 'size distortion' in results.

Doornik and Hansen (1994) proposed a single omnibus test statistic that combines the measures of skewness and kurtosis, known as the Doornik-Hansen test. This test was found to have good power compared with other multi-variate normality tests and it was able to achieve the nominal significance level too. Since our dataset is very large, the J-B test and the Doornik-Hansen test have been used to test for normality.

For both the tests, the null hypothesis is that data follows a normal distribution against the alternative of non-normal distribution.

Symbolically, $\mathrm{H}_{0}: \mathrm{X} \sim \mathrm{N}($.) and

$$
\mathrm{H}_{1}: \mathrm{X} \neq \mathrm{N}(.)
$$

where, $\mathrm{H}_{0}$ and $\mathrm{H}_{1}$ are the null and alternative hypothesis respectively, and

$$
\mathrm{N}(\text {.) is the normal probability distribution function. }
$$


Dickey-Fuller Unit Root Test and KPSS Test:A stationary process is a process whose statistical properties do not change with change in time at which the series is observed. Consequently, statistical parameters like mean, variance, etc. stay steady over time and do not follow any trends.

The most commonly used stationarity testsare the Dickey - Fuller Test and the KPSS test.

In an autoregressive series $\mathrm{Y}_{\mathrm{t}}=\theta \mathrm{Y}_{\mathrm{t}-1}+\mathrm{U}_{\mathrm{t}}$, where $\theta$ is an unknown constant, the Dickey - Fuller Test is based on testing the null hypothesis that the series has a unit root or $\theta=1$ i.e. $\mathrm{H}_{0}: \theta=1$ against the one - sided alternative hypothesis that the series is stationary or $\mathrm{H}_{1}: \theta<1$. Alternatively, the model can be specified as: $\Delta \mathrm{Y}_{\mathrm{t}}=$ $(\theta-1) \mathrm{Y}_{\mathrm{t}-1}+\mathrm{U}_{\mathrm{t}}$, where $\pi=\theta-1$ so that test of $\theta=1$ (there is a unit root in $\mathrm{Y}_{\mathrm{t}}$ ) is translated into test of $\mathrm{H}_{0}: \pi=0$ and the alternative hypothesis $\mathrm{H}_{\mathrm{A}}: \pi<0$. Since rejection ' of null hypothesis needs substantial evidence against it, most of the series are considered as having a unit root. So, the KPSS (Kwiatkowski-Phillips-SchmidtShin) test has been used to confirm the results obtained from the Dickey - Fuller Test. The KPSS test tests the null hypothesis that the series is stationary and is complementary to the unit root test and using both the tests helps one to know whether the series is stationary.

Relative Price Strength: It compares the performance of a security, industry, portfolio or index relative to some benchmark, usually an industry or market index; it thus points to stocks exhibiting strong price momentum. Relative strength is considered a useful indicator because if a portfolio displays positive relative strength, it is premised that this trend will continue in the future. Relative strength has been calculated as:

Relative strength $=[\{(E S G$ Index value at end of period $t / E S G$ Index value at beginning of period $t) \div($ Benchmark Index value at end of period $t /$ Benchmark Index value at beginning of period $t)\}-1] \times 100$.

Relative strength can be calculated over whatever time period is desired - week to week, month to month or year to year basis (Bajkowski, 1997). Studies have shown that ranking stocks based on price performance over periods less than one month or longer than 12 months does not yield profitable results. Masonson splits the difference and uses six months relative strength in his analysis (Thorp, 2011). Hence, relative price strength has been computed over six month period for the entire study period.

Sharpe Ratio:Developed by the Nobel laureate, William F. Sharpe, it is one of the most popular measures of risk-adjusted return, used to evaluate the performance of a portfolio or index. It is the average return earned by a fund, portfolio or index, in excess of the risk-free rate of return per unit of risk or volatility and is calculated as:

Sharpe ratio $=\left(R_{x}-R_{f}\right) / \sigma_{x}$, where,

$R_{x}$ is fund, portfolio or index return,

$\mathrm{R}_{\mathrm{f}}$ is risk-free rate, and

$\sigma_{\mathrm{x}}$ is the standard deviation of the portfolio or index returns.

But, the Sharpe measure assumes that return data is normally distributed. If the return data is not normally distributed, the estimates of Sharpe ratio may be misleading.

Capital Asset Pricing Model (CAPM): The main model used to assess performance is the single index Capital Asset Pricing Model or the CAPM. The intercept of this model ' $\alpha$ ' or the Jensen's Alpha is extensively used as a standard measure to evaluate fund or index performance since it measures the excess return of an index or portfolio in comparison to the average market return. Jensen (1968) used the 
CAPM to estimate the extra return earned by a fund compared to market benchmark. Since then, Jensen's alpha which is the excess return over the security market line in the CAPM, is used to measure outperformance or underperformance as compared to the given market proxy as superior performance has consistently positive random error terms and inferior performance has consistently negative random error terms, which are picked up in the intercept alpha.

The Jensen's alpha is estimated based on the standard capital asset pricing model given by Sharpe (1964) and Lintner (1965). Empirically, the model can be described as:

$R_{p}=R_{f}+\beta_{p m}\left(R_{m}-R_{f}\right)+e_{p}$, Equation (1)

where, $R_{p}=$ return on portfolio $p$,

$\mathrm{R}_{\mathrm{f}}=$ risk - free interest rate,

$\mathrm{R}_{\mathrm{m}}=$ return on the benchmark asset or market portfolio,

$\beta_{\mathrm{pm}}=$ systematic risk or market $\beta$ for the portfolio, and

$\mathrm{e}_{\mathrm{p}}=$ forecast error with zero mean.

Jensen (1968) used the CAPM to measure fund, index or portfolio performance by including a constant in equation (1) such that

$R_{p}-R_{f}=\alpha+\beta_{p m}\left(R_{m}-R_{f}\right)+e_{p}$,

where, $R_{p}-R_{f}=$ excess return of the portfolio (i.e. excess return of ESG index

over risk-free rate),

$\alpha=a$ constant (Jensen's alpha) that measures abnormal performance of

the fund, portfolio or index,

$R_{m}-R_{f}=$ excess return of the benchmark index (i.e. Nifty) over risk -

free rate,

$\beta_{\mathrm{pm}}=$ systematic risk or market $\beta$ for the portfolio.

The Jensen's alpha is extensively used in evaluating fund or index performance, a positive alpha showing superior performance, a negative alpha showing inferior performance and a zero value of alpha showing neutral or no difference in performance.

Brown Forsythe Levene's Test:Levene's test is very useful for testing the equality of variances of $k$ populations under non - normality conditions. It computes the absolute differences between each observation and the mean of its group and performs a one - way analysis of variances on those differences. Brown and Forsythe (1974) improved the robustness of the Levene's test to non - normality by replacing the group means by median, which is a better estimator of location. This test, called the Brown Forsythe Levene's (1974) test has been used to determine the significance of the difference in the variances of the two indices. This test performs a one - way analysis of variance on those differences. The resultant $\mathrm{F}$ statistic is:

$\mathrm{F}=\frac{N-k}{k-1} \cdot \frac{\sum_{i=1}^{k}\left(\overline{d_{l}}-\overline{d)^{2}}\right.}{\sum_{i=1}^{k} \sum_{i=1}^{n_{i}} n_{i}\left(d_{i j}-\overline{d_{l}}\right)^{2}}$

where, $\mathrm{d}_{\mathrm{ij}}=\left|x_{i j}-\bar{x}_{l}\right|$, for $\mathrm{i}=1, \ldots, \mathrm{k} \& \mathrm{j}=1, \ldots, \mathrm{n}$. 
https://ir.iba.edu.pk/businessreview/vol10/iss2/7

DOI: https://doi.org/10.54784/1990-6587.1356

Business Review - Volume 10 Number 2

July - December 2015

An insignificant F-statistic, indicates no significant difference in the variances.

\section{Examining the financial performance of S\&P ESG India Index: Analysis and Discussion}

The present study has used the comparison of returns and risks of S\&P ESG India Index with the market benchmark CNX Nifty 50 to analyse the performance of ESG indices in India. The performance characteristics compared are price, returns and risk. The following sub-section discusses the analysis of the performance of the ESG Index, and interpretation of the results.

\section{Data pre-testing}

Before performing any statistical analysis, the data was screened for normality and stationarity, as the assumptions of normality and stationarity of the data are implicit in the analysis tests used for hypothesis testing. Table 1 presents the result of normality tests for the data.

Table 1: Results of the normality tests for S\&P ESG India Index and CNX Nifty 50 Index

\begin{tabular}{l|l|l|l|c}
\hline \multirow{2}{*}{ Test for Normality } & \multicolumn{2}{l|}{ S\&P ESG India Index } & \multicolumn{2}{l}{ CNX Nifty 50 Index } \\
\cline { 2 - 5 } & Test Statistic & P-Value & Test Statistic & P-Value \\
\hline Jarque-Bera test & 28.0376 & $8.16045 \mathrm{e}-007$ & 14.6782 & 0.0006496 \\
\hline Doornik-Hansen test & 18.9255 & $7.76942 \mathrm{e}-005$ & 18.1153 & 0.00011650 \\
\hline
\end{tabular}

The results of the Jarque-Bera test and the more efficient Doornik-Hansen test for normality show rejection of the null hypothesis of normality for the S\&P ESG India Index and CNX Nifty 50 Index excess return series, implying that the excess return series of both the indices is not normally distributed, as is generally the case with most of the return series.

Tables 2(a) and 2(b)present the results of two tests for testing the stationarity of the excess return data series - the Augmented Dickey-Fuller (ADF) test and the KPSS test. While the ADF test tests the null hypothesis of presence of a unit root against the alternative of stationarity; the KPSS tests the null hypothesis of stationarity against the alternative of a unit root.

Table 2(a): Results of the ADF test for S\&P ESG India Index and CNX Nifty 50 Index

\begin{tabular}{|c|c|c|c|c}
\hline \multirow{2}{*}{$\begin{array}{c}\text { Augmented Dickey- } \\
\text { Fuller Test }\end{array}$} & \multicolumn{2}{|c|}{ S\&P ESG India Index } & \multicolumn{2}{c}{ CNX Nifty 50 Index } \\
\cline { 2 - 5 } & Test Statistic & P-Value & Test Statistic & P-Value \\
\hline Without trend & -6.2094 & $1.553 \mathrm{e}-006$ & -7.01555 & $9.301 \mathrm{e}-008$ \\
\hline With trend & -6.15481 & $1.588 \mathrm{e}-005$ & -6.99861 & $8.883 \mathrm{e}-007$ \\
\hline
\end{tabular}


https://ir.iba.edu.pk/businessreview/vol10/iss2/7

DOI: https://doi.org/10.54784/1990-6587.1356

Business Review - Volume 10 Number 2

July - December 2015

Table 2(b): Results of the KPSS stationarity test for S\&P ESG India Index and CNX Nifty 50 Index

\begin{tabular}{c|c|c|c|}
\hline \multirow{2}{*}{ KPSS Test } & \multirow{2}{*}{$\begin{array}{c}|c| \\
\text { Vest Critical } \\
\text { Values }\end{array}$} & & \multicolumn{2}{|c|}{ Test Statistic } \\
$1 \%$ significance & 0.729 & & CNX Nifty 50 Index \\
\hline $5 \%$ significance & 0.468 & 0.157336 & 0.102121 \\
\hline $10 \%$ significance & 0.350 & & \\
\hline
\end{tabular}

The results of the Augmented Dickey-Fuller Test for stationarity of the excess return series of S\&P ESG India Index and CNX Nifty 50 Index indicate rejection of the null hypothesis of unit root in favour of the alternative of stationarity. Hence, both the return series are stationary, with and without time trend. The results of the KPSS test for stationarity show that the test statistics for both the indices are less than the test critical values at the $1 \%$, $5 \%$ and $10 \%$ significance levels, implying that the null hypothesis of stationarity cannot be rejected, and hence, the two return series are stationary. This is in conformity with the results obtained from ADF Test.

\section{Preliminary Analysis}

After testing for normality and stationarity, the data was subject to preliminary analysis which comprised of computation of summary statistics for the data, correlations and calculation of parameters like relative price strength, annualised and average monthly returns, beta and risk adjusted ratios. This analysis gives us preliminary findings about the performance of the ESG India Index in comparison to the benchmark CNX Nifty 50 Index.

Table 3 presents the summary statistics of the monthly excess returns of ESG India Index and CNX Nifty 50 Index.

Table 3: Summary statistics for monthly excess return data for ESG India Index and CNX Nifty 50 Index

\begin{tabular}{|c|c|c|}
\hline Variables & $\begin{array}{c}\text { ESG Index Monthly Excess } \\
\text { Returns }\end{array}$ & $\begin{array}{c}\text { CNX Nifty 50 Monthly Excess } \\
\text { Returns }\end{array}$ \\
\hline Mean & -0.00792045 & -0.0140334 \\
\hline Median & -0.0107208 & -0.0144810 \\
\hline Minimum & -0.268913 & -0.284103 \\
\hline Maximum & 0.350719 & 0.260660 \\
\hline Standard Deviation & 0.0932868 & 0.0812578 \\
\hline C.V. & 11.7780 & 5.79032 \\
\hline Skewness & 0.622409 & 0.000778352 \\
\hline Ex. Kurtosis & 3.10893 & 2.42307 \\
\hline Missing Observations & 0 & 0 \\
\hline Jarques Bera -Test Statistic & 28.0376 & 14.6782 \\
\hline - Probability & $8.16045 \mathrm{e}-007$ & 0.000649644 \\
\hline
\end{tabular}


The mean excess return $(0.7920 \%)$ of S\&P ESG India Index during the study period is higher than that of the benchmark CNX Nifty 50 Index $(-1.4033 \%)$, suggesting that the ESG India Index outperformed the benchmark CNX Nifty 50 Index. A brief comparison of the standard deviations or variability of the monthly excess returns of the ESG India Index and the CNX Nifty 50 Index reveal that the standard deviation (9.32) of the ESG India Index is marginally higher than that of CNX Nifty 50 (8.13), implying that the volatility of returns of the ESG India Index is greater than that of the benchmark CNX Nifty 50. Table 4 presents the results of correlation between the returns of the two indices under study. The result shows very high degree of positive correlation between them.

Table 4: Correlation Matrix

\begin{tabular}{|c|c|c}
\hline $\begin{array}{c}\text { ESG Index Monthly Excess } \\
\text { Returns }\end{array}$ & $\begin{array}{c}\text { CNX Nifty 50 Monthly Excess } \\
\text { Returns }\end{array}$ & $\begin{array}{c}\text { ESG Index Monthly Excess } \\
\text { Returns }\end{array}$ \\
\hline 1.0000 & $0.9656^{* * *}$ & $\begin{array}{c}\text { CNX Nifty 50 Monthly Excess } \\
\text { Returns }\end{array}$ \\
\hline
\end{tabular}

Table 5 presents the results of the computations of the relative price strength (for the 5-year period), average annual relative price strength, total return of the two indices for the 5year period, average annualised returns, average monthly returns, reward to risk ratio and Sharpe ratio.

Table 5: Estimations of Relative Price Strength, Average Returns, Beta, and Risk Adjusted Return Ratios

\begin{tabular}{|c|c|c|}
\hline Particulars & S\&P ESG India Index & CNX Nifty 50 Index \\
\hline Relative Price Strength (over the 5 year period) & $38.60 \%$ & \\
\hline Average annual relative price strength & $7.66 \%$ & $17.47 \%$ \\
\hline Total return (over the 5 year period) & $60.56 \%$ & $0.81 \%$ \\
\hline Average annualised return & $22.67 \%$ & 1.00 \\
\hline Average monthly return & $1.21 \%$ & 2.1494 \\
\hline Beta (relative to market benchmark) & 1.1085 & 1.1649 \\
\hline Reward to Risk Ratio & 6.4914 & \\
\hline Sharpe Ratio & 5.6338 & \\
\hline
\end{tabular}

The average annual price strength of ESG India Index relative to CNX Nifty is 7.66 $\%$ and its average annualised returns, average monthly returns, reward to risk ratio and Sharpe ratio is higher than the corresponding estimates for CNX Nifty 50 Index, showing superior performance by ESG India Index as compared to Nifty 50 Index, in terms of price, returns as well as risk adjusted ratios like the reward to risk ratio and the Sharpe ratio.

Similar results are evidenced by the graphs of rolling 12-monthly correlation between the returns of the two indices, as shown in figure 1; graph of the historical price performance of the 2 indices during the study period (showing consistent outperformance after a brief period of 9-months post launch of ESG Index), as shown by figure 2; graphical 
comparison of the returns of the two indices, as shown by figure 3; and graphical comparison of the volatility of the two indices for the study period, as depicted by figure 4 .

Figure 1: Rolling 12-month correlation of ESG India Index returns with Nifty 50 Index returns

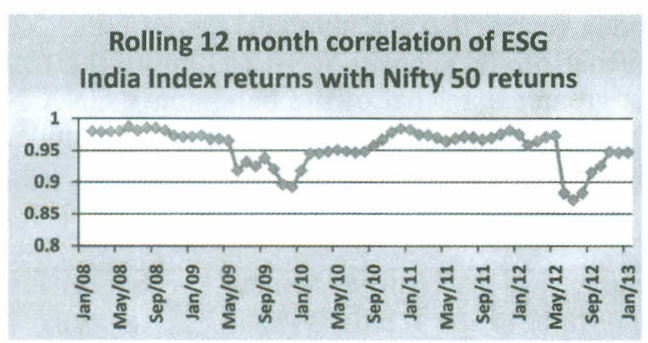

Figure 2: Historical price performance of S\&P ESG India Index and CNX Nifty 50 Index

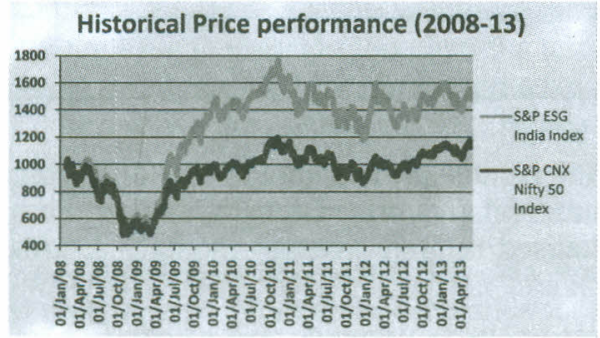

Figure 3: Return comparison of S\&P ESG India Index and CNX Nifty 50 Index

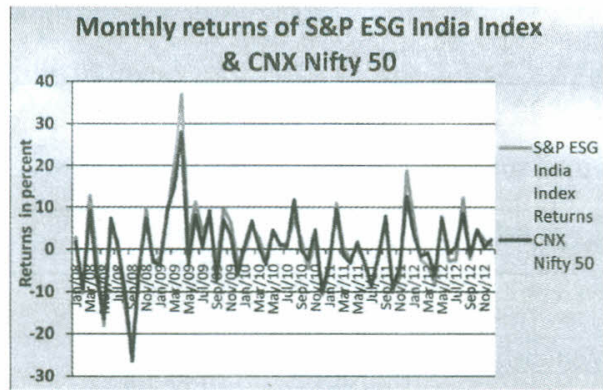

Figure 4: Volatility of ESG India Index and CNX Nifty 50

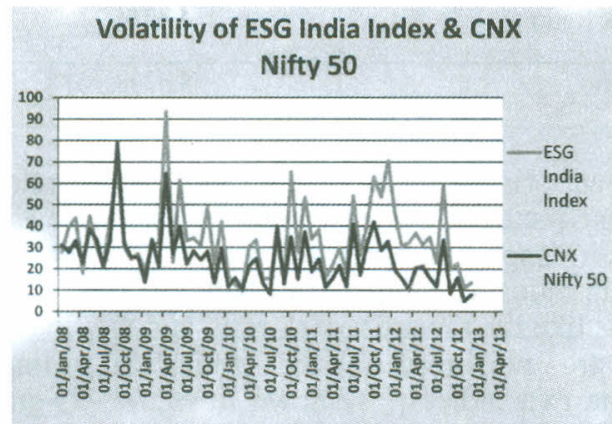


But, these are preliminary findings and more appropriate risk-adjusted measures like Jensen's Measure are required for making valid inferences.

\section{CAPM and Brown-Forsythe Levene's test}

The main model and test used for analysing the performance of the S\&P ESG India Index as compared to the benchmark CNX Nifty 50, in terms of returns and risk are CAPM and Brown-Forsythe Levene's test.

For assessing the excess returns of the S\&P ESG India Index, over and above that of the excess returns of the market benchmark Nifty 50, the study has used CAPM regression, which has become a standard measure of performance evaluation and has been extensively used in literature to evaluate index performance, and report on the statistical significance of the over or under performance(Hassan, Antoniou, and Paudyal, 2005). For assessing the volatility, the study has used the Brown-Forsythe Levene's test, which assesses the difference in volatility of the two indices, measured by the variances of the return series.

Table 6 shows the estimations of the Jensen's measure of outperformance based on the Capital Asset Pricing Model.

Table 6: Summary performance, CAPM regressions of S\&P ESG India Index from 2008 to 2013 (Regressions are based on monthly excess returns, Number of observations: 60)

\begin{tabular}{|c|c|c|c|c|c|}
\hline & Coefficient & Std. Error & t-ratio & p-value & \\
\hline Alpha (intercept) & 0.007636 & 0.003206 & 2.381708 & 0.020534 & $* *$ \\
\hline Beta & 1.10854 & 0.039199 & 28.27945 & $<0.00001$ & $* * *$ \\
\hline
\end{tabular}

\begin{tabular}{|c|c|c|c|}
\hline Mean dependent var & -0.007920 & S.D. dependent var & 0.093287 \\
\hline Sum squared resid & 0.034719 & S.E. of regression & 0.024466 \\
\hline R-squared & 0.932379 & Adjusted R-squared & 0.931214 \\
\hline F(1,58) & 799.7272 & P-value(F) & $1.27 \mathrm{e}-35$ \\
\hline Durbin-Watson & 1.841064 & P-value(DW) & 0.264925 \\
\hline
\end{tabular}

$* * \mathrm{p}$-value $<0.05$ or $\mathrm{p}$-value value is significant at the 0.05 level,

$* * * p$-value $<0.001$ or $p$-value value is significant at the 0.001 level.

The output of the CAPM regression shown in Table 6 shows that the model is good, indicated by the large and significant F-statistic. The Durbin-Watson statistics with an insignificant $\mathrm{p}$-value shows that there is no serial correlation. The results of the estimation as presented in table 6 show that the ESG India Index outperforms the benchmark. The alpha of the ESG India Index $(\alpha=0.7636 \%, t=2.3817)$ is statistically different from zero.This positive value of alpha represents the excess returns of ESG India Index over and above the excess returns of the benchmark CNX Nifty 50 Index. The p-value of 0.020534 indicates significance of the coefficient at the $5 \%$ level.

The Brown-Forsythe Levene's Test has been used to test the difference in the volatility (as measured by the variances) of the returns of the two indices. It has been preferred over the F-Test as the F-Test is sensitive to violation of the normality assumption and the return series data is not normally distributed, as seen earlier. Table 7 presents the result of the Brown-Forsythe Levene's Test for the difference in volatility of the two indices. 
Table 7: Results of the Brown-Forsythe Levene's Test for hypothesis testing

\begin{tabular}{|c|c|c|c|c|}
\hline \multirow{2}{*}{ Particulars } & \multicolumn{2}{|c|}{ Test Statistic } & \multirow{2}{*}{ df } & \multirow{2}{*}{ P-value } \\
\cline { 2 - 4 } & Parameter & Value & & \\
\hline Brown-Forsythe Levene's Test & 'F' & 3.365219 & 1 & 0.07163 \\
\hline
\end{tabular}

Table 7 shows that the p-valueis insignificant, implying that there is no significant difference in the variances of the two indices. So, it can be inferred that though the returns of S\&P ESG India Index are slightly higher than those of CNX Nifty 50, there is no significant difference in the variance (and hence, the volatility) of the two indices. Hence, the S\&P ESG India Index slightly outperforms the CNX Nifty 50 Index, over the period of study, and since there is no difference in volatility, the investors are not exposed to any additional risk, as was opined by some analysts.

\section{Conclusion}

The use of ESG criteria in investment decision-making is increasingly growing in popularity across the world. Academic and practitioner research around the world has proved that better ESG performance by companies leads to reduced risks, improved financial performance, better stock market valuations and hence, enhanced returns for investors investing in stocks of such companies. This has led to development of ESG indices and funds to enable investors to identify high ESG performing companies for investment purposes. Yet, ESG investment has often been criticised of limiting the investible universe of stocks and thus, limiting portfolio diversification, increasing risk and reducing returns. Absence of convincing research on the performance of ESG investment has been one of the major factors responsible for the slow adoption of this valuable investment approach in developing economies like India. But, the results of this study clearly show that any assumption that ESG investment results in reduced returns for investors is not sustainable. The results provide first convincing empirical evidence in Indian context that ESG investment enhances investment returns, as is indicated by the relatively higher risk-adjusted returns, captured in the positive value of alpha in CAPM. These findings are in conformity with results obtained from similar studies in other countries. This study has important implications not only for investors but also for asset managers and investment advisors. It indicates that investors can choose to invest according to ESG criteria without paying a penalty in investment returns. In this context, this paper makes valuable contribution to empirical literature on ESG investment in developing economies, specifically India. Though there have been a couple of studies analysing the performance of ESG index in India, this study employs greater methodological rigour than that used by the past studies and is the first study which comprehensively analyses the performance of ESG index in India.

But, the study was constrained by a few limitations. Due to the novelty of the concept in Indian market, data was available only for a period of five years since the S\&P ESG India Index was launched in January 2008 only and post 2013, data could not be used as change in index maintenance services caused a change in index constitution. The present study has used single index CAPM for comparison of index performance. As data on company classifications and index prices becomes available over a longer period, more sophisticated multi-factor models like the Fama-French model can be employed to analyse index performance.

Future research could be conducted with a focus on addressing these limitations of the present study. 迷随 
https://ir.iba.edu.pk/businessreview/vol10/iss2/7

DOI: https://doi.org/10.54784/1990-6587.1356

Business Review - Volume 10 Number 2

July - December 2015

\section{References}

Abramson, L., \& Chung, D. (2000). Socially Responsible Investing: Viable for Value Investors. The Journal of Investing, Vol.9, No.3, 73-80.

Adajania, K. (2010, October 26). Mutual Funds: Balancing Ethics With Performance. Retrieved July 1, 2012, from Livemint: http://www.livemint.com/2010/10/.../Mutual-FundsBalancing-Ethics.html

Bajkowski, J. (1997, August). Seeking Stocks With Momentum: A Look at Relative Strength Measures. Retrieved February 18, 2015, from American Association of Individual Investors Journal: http://www.aaii.com/journal/article/seeking-stocks-with-momentum-a-look-atrelative-strength-measures

Balasubramanian, B. N., Black, B., \& Khanna, V. (2009, July). Firm - level Corporate Governance in Emerging Markets: A Case Study of India. Retrieved January 6, 2012, from Social Science Research Network: http://ssrn.com/abstract=992529

Banerjee, A., \& Orzano, M. (2010, March). Performance Analysis of Two Indian Equity Indices. Retrieved June 26, 2013, from Standard \& Poor's Indices:

https://us.spindices.com/documents/research/Performance Analysis of Two Indian Equity Indices 2010Mar.pdf

Bauer, R., Derwall, J., \& Otten, R. (2007). The Ethical Mutual Fund Performance Debate: New Evidence From Canada. Journal of Business Ethics, 70 , 111-124.

Bauer, R., Otten, R., \& Rad, A. T. (2004, March 15). Ethical investing in Australia: Is there a financial penalty. Retrieved July 10, 2012, from Social Science Research Network:

http://ssrn.com/abstract=567127

Bello, Z. (2005). Socially Responsible Investing and Portfolio Diversification. Retrieved July 4, 2012, from http://ssrn.com/abstract=524962

Brown, M. B., \& Forsythe, A. B. (1974, June). Robust Tests for the Equality of Variances.

Retrieved February 18, 2015, from Journal of the American Statistical Association, Vol.69: http://www.jstor.org/stable/2285659

cKinetics. (2013). Cracking the Conundrum: An investor and policy view to leverage standardization of environmental and social disclosure and reporting. Retrieved February 18, 2015, from cKinetics: http://www.ckinetics.com/crackingtheconundrum/

Damodaran, A. (n.d.). A Risk Free Rate. Retrieved March 10, 2015, from http://people.stern.nyu.edu/adamodar/pdfiles/eqnotes/discrate1.pdf

Doornik, J. A., \& Hansen, H. (1994, November 24). An omnibus test for univariate and multivariate normality. Retrieved March 10, 2015, from Jurgen A Doornik:

http://www.doornik.com/research/normal2.pdf

Dowell, G., Hart, S., \& Yeung, B. (August 2000). Do Corporate Global Environmental Standards Create or Destroy Market Value. Management Science, Vol.46, No.8, pp.10591074.

Eurosif. (2009). Investment Consultants \& Responsible Investment Study. Retrieved June 21, 2014, from Eurosif: http://www.eurosif.org/wpcontent/uploads/2014/06/eurosif_investment_consultants_ri_study.pdf

Global Sustainable Investment Alliance (GSIA). (2013, January). 2012 Global Sustainable Investment Review. Retrieved June 01, 2014, from Global Sustainable Investment Alliance: 
http://gsiareview2012.gsi-

alliance.org/pubData/source/Global\%20Sustainable\%20Investement\%20Alliance.pdf

Global Sustainable Investment Alliance. (2013). Global Sustainable Investment Review 2012.

Retrieved June 15, 2014, from Global Sustainable Investment Alliance:

http://gsiareview2012.gsi-

alliance.org/pubData/source/Global\%20Sustainable\%20Investement\%20Alliance.pdf

Guenster, N., Derwall, J., Bauer, R., \& Koedijk, K. (2005, July 25). The Economic Value of Corporate Eco-Efficiency, Working Paper, Erasmus University. Retrieved March 24, 2015, from SRI Studies: http://www.sristudies.org/Guenster+(2005)

Hassan, A., Antoniou, A., \& Paudyal, D. K. (2005). Impact Of Ethical Screening On Investment Performance: The Case Of The Dow Jones Islamic Index. Retrieved February 18, 2015, from Islamic Research and Training Institute:

http://www.irti.org/English/Research/Documents/IES/094.pdf

Havemann, R., \& Webster, P. (1999, September). Does Ethical Investment Pay. Retrieved April 4, 2012, from EIRIS: http://www.eiris.org.

Investopedia. (n.d.). Central Limit Theorem - CLT. Retrieved February 18, 2015, from Investopedia: http://www.investopedia.com/terms/c/central_limit_theorem.asp

Investopedia. (n.d.). Standard Deviation. Retrieved February 18, 2015, from Investopedia: $\mathrm{http}: / / \mathrm{www}$.investopedia.com/terms/s/standarddeviation.asp

Jemel, H. (September 2008). The Effects of Corporate Environmental, Social and Governance Involvement on its Financial Performances: An Old Ongoing Debate. Cranfield.

Jensen, M. C. (1968). The Performance Of Mutual Funds In The Period 1945-1964. The Journal of finance, 23 , 389-416.

Kreander, N., Gray, R. H., Power, D. M., \& Sinclair, C. D. (2005). Evaluating the performance of Ethical and Non - Ethical Funds: A Matched Pair Analysis. Journal of Business Finance and Accounting, Vol.32, No. 7 \& 8, 1465-1493.

Krosinsky, C., \& Robins, N. (2008). Sustainable Investing: The Art of Long - Term Performance. London, UK: Earthscan Publishers.

Lintner, J. (1965). The Valuation of Risk Assets and the Selection of Risky Investments in Stock Portfolios and Capital Budgets. The Review of Economics and Statistics, 47(1) , 13-37.

Norup, A., \& Gottlieb, M. (2011, August). Socially Responsible Investing: An Assessment of the concept on the Danish Market. Retrieved February 20, 2012, from Copenhagen Business School: http://www.studenttheses.cbs.dk/bitstream/.../adam_norup_og_mads_gottlieb.pdf

Orlitzky, M., Schmidt, F., \& Rynes, S. (2003, March). Corporate Social and Financial Performance: A Meta - Analysis. Retrieved July 4, 2012, from US Social Investment Forum: http://ussif.org/pdf/research/Moskowitz/2004 Winning Paper - Moskowitz.pdf

Renneboog, L., Horst, J. T., \& Zhang, C. (2007, June). Socially Responsible Investments: Methodology, Risk Exposure and Performance. Retrieved July 9, 2012, from Social Science Research Network: http://ssrn.com/abstract_id=985267

Renneboog, L., Horst, J. T., \& Zhang, C. (2007, May). The Price of Ethics: Evidence from Socially Responsible Mutual Funds. Retrieved February 9, 2012, from Social Science Research Network: http://ssrn.com/abstract_id=985265

Shapiro, S. S., \& Wilk, M. B. (1965, December). An analysis of variance test for normality (complete samples). Retrieved March 10, 2015, from Jstor: 
http://links.jstor.org/sici?sici=0006-

3444\%28196512\%2952\%3A3\%2F4\%3C591\%3AAAOVTF\%3E2.0.CO\%3B2-B

Sharpe, W. F. (1964). Capital Asset Prices: A Theory of Market Equilibrium under Conditions of Risk. The Journal of Finance, 19(3) , 425-442.

Statman, M. (2005, May). Socially responsible indexes: Composition, performance and tracking errors. Retrieved July 10, 2012, from Social Science Research Network: http://ssrn.com/abstract $=705344$

Terayama, M. (2010, October 5). ESG Factors in Corporate Valuation. Retrieved June 10, 2012, from Mercer Consulting:

http://www.mercer.com/referencecontent.htm?idContent=1395145

Thorpe, W. A. (2011, April). Using Relative Strength Analysis to Invest in ETFs. Retrieved February 18, 2015, from Computerized Investing: http://www.aaii.com/files/ci/Feature042011.pdf

Remember, we're in a hall of mirrors. To succeed, you must avoid the trap of being overly dazzled by your own image. John R. Beckett

David Olive \& Gita Piramal, The Quotable Tycoon: A treasury of business quotations, Page 71 